\title{
Smoking Habit and Correlation with Hand Eczema in Healthcare Workers in the Time of COVID-19
}

\author{
Anca E. Chiriac¹, Doina Azoicai1, Uwe Wollina², Anca Chiriac ${ }^{3,4,5}$, Cristian Podoleanu6, \\ Simona Stolnicu 7,8 \\ 1 Department of Epidemiology, “Grigore T. Popa” University of Medicine and Pharmacy, lași, Romania \\ 2 Department of Dermatology and Allergology, Städtisches Klinikum, Dresden, Germany \\ 3 Department of Dermatology, Nicolina Medical Center, Iași, Romania \\ ${ }^{4}$ Apollonia University, Iași, Romania \\ 5 "Petru Poni" Institute of Macromolecular Chemistry, Romanian Academy, Iași, Romania \\ 6 Department of Internal Medicine IV, “George Emil Palade” University of Medicine, Pharmacy, Science and Technology, Târgu \\ Mureș, Romania \\ 7 Department of Pathology, "George Emil Palade” University of Medicine, Pharmacy, Science and Technology, Târgu Mureș, Romania \\ 8 Histopat Invest Laboratory, Târgu Mures, Romania
}

\section{CORRESPONDENCE}

\section{Cristian Podoleanu}

Str. Gheorghe Marinescu nr. 38

540139 Târgu Mureș, Romania

Tel: +40 265215551

E-mail: podoleanu@me.com

\section{ARTICLE HISTORY}

Received: November 2, 2020

Accepted: December 6, 2020

Anca E. Chiriac • Str. Universitătii nr. 16, 700115 lași, Romania. Tel: +40232301600

Doina Azoicai • Str. Universitătii nr. 16, 700115 lași, Romania. Tel: +40 232301600

Uwe Wollina - Academic Teaching Hospital,

Friedrichstrasse 41, 01067 Dresden, Germany. Tel: +49

03514803901

Anca Chiriac • Str. Hatman Sendrea nr. 2, 700613 lași, Romania. Tel: +40332808703

Simona Stolnicu • Str. Gheorghe Marinescu nr. 38 540139 Târgu Mureș, Romania. Tel: +40 26521555

\section{ABSTRACT}

Background: Hand eczema, in time of COVID-19, is one of the most frequently diagnosed skin disorders in nurses. In this study, we sought to investigate whether smoking could be an additional risk factor for hand eczema in nurses during the COVID-19 pandemic. Method: Using a questionnaire about smoking details and hand eczema, we conducted a study among nurses involved in the frontline management of COVID-19 patients. A total of 1,000 questionnaires were sent out. The questionnaires were anonymous and based on self-reported answers, with no clinical examination or medical data evaluation. All nurses enrolled in the study were women, working in shifts for the last three months since the start of the COVID-19 pandemic. Results: Two-hundred forty-seven questionnaires were accepted for the study, after eliminating non-responders and nurses without hand eczema. The majority of nurses denied smoking (87.85\%) in the past and at the moment of the study. Statistics related to years of smoking and occurrence of hand eczema showed no increase in the number of cases in correlation with the number of years of smoking. Similarly, a random distribution of cases of hand eczema was observed when compared to the number of cigarettes per day. Conclusion: Our data does not support the hypothesis that smoking is an independent risk factor for the development of occupational hand eczema during the COVID-19 pandemic.

Keywords: smoking, risk factor, hand eczema, COVID-19 


\section{INTRODUCTION}

After the outbreak of the COVID-19 pandemic in Wuhan, China, healthcare workers have been exposed to intensified hygienic measures to prevent the spread of the disease. Working in wet conditions, and frequent handwashing and disinfection contribute to the development of irritant hand eczema. The frequency of hand eczema in the pre-COVID times has been estimated to be between $20-50 \%$.

Since the COVID-19 pandemic started, hand eczema has been the most frequently diagnosed occupational skin disorder among nurses. Two recently published Chinese studies from Hubei, China, reported hand eczema in $71 \%$ to $97 \%$ of healthcare workers during the pandemic. ${ }^{1,2}$ There is published evidence that smoking may be an important additional risk factor for both allergic and irritant contact dermatitis, as well as hand eczema in general. ${ }^{3,4}$

In this study, we sought to investigate whether smoking could be an additional risk factor for hand eczema in nurses during the COVID-19 pandemic.

\section{MATERIAL AND METHODS}

Using a questionnaire about smoking details and hand eczema, we conducted a study among nurses involved in the frontline management of COVID-19 patients. One thousand questionnaires were sent out; data were collected anonymously. All nurses enrolled in the study were women, working in shifts for the last three months since the pandemic started.

The study was approved by the ethics committee of the institution, and all study procedures were in accordance with the Declaration of Helsinki.

\section{RESULTS}

A total of 247 questionnaires were accepted for the study, after eliminating non-responders and nurses without hand eczema. The questionnaires were anonymous and based on self-reported answers, with no clinical examination or medical data evaluation.

Smoking habit was assessed in order to find any correlation with the occurrence of hand eczema. The majority of
TABLE 1. Smoking as a hobby

\begin{tabular}{lll}
\hline Current & Count & Percent \\
\hline Yes & 27 & 10.93 \\
No & 217 & 87.85 \\
Missing & 3 & 1.22 \\
\hline
\end{tabular}

TABLE 2. History of smoking

\begin{tabular}{lll}
\hline Former & Count & Percent \\
\hline Yes & 18 & 7.29 \\
No & 3 & 1.21 \\
Missing & 226 & 91.50 \\
\hline
\end{tabular}

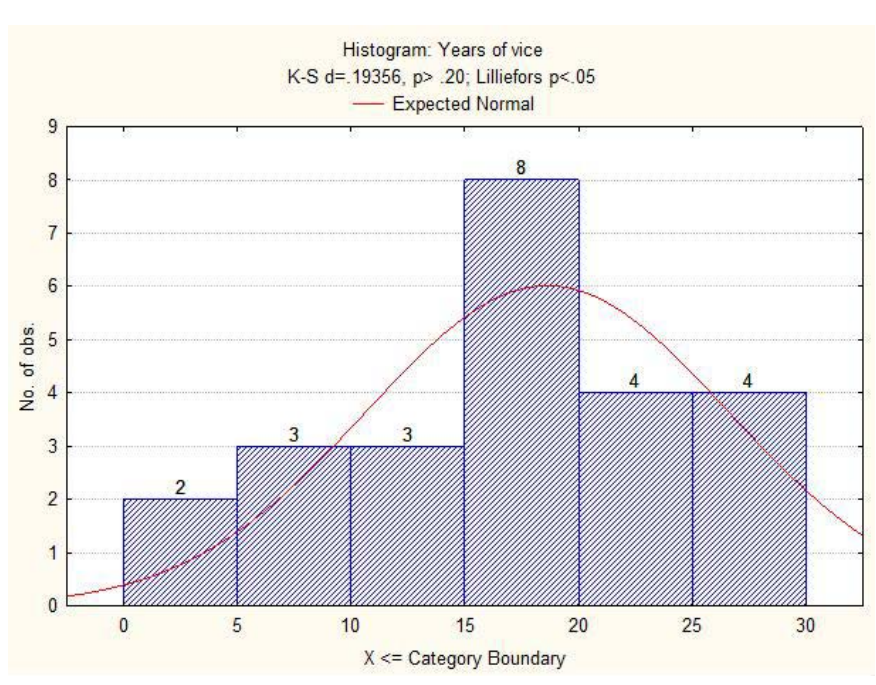

FIGURE 1. Distribution of cases of hand eczema and years of smoking

nurses denied smoking (87.85\%) in the past and at the moment of the study (Table 1).

To the question: "Were you a smoker in the past and stopped now?", the great majority did not respond (Table 2). Statistics related to years of smoking and occurrence of hand eczema showed no increase in the number of cases in correlation with the number of years of smoking (Table 3 , Figure 1). Similarly, a random distribution of cases of hand eczema was observed when compared to the number of cigarettes per day (Tables 4 and 5; Figure 2).

TABLE 3. Descriptive statistics of years of smoking within nurses with hand eczema

\begin{tabular}{lllllllllll}
\hline & Valid N & Mean & $\begin{array}{l}\text { Confidence } \\
\mathbf{- 9 5} \%\end{array}$ & $\begin{array}{l}\text { Confidence } \\
+\mathbf{9 5 \%}\end{array}$ & Median & Min & Max & $\begin{array}{l}\text { Lower - } \\
\text { Quartile }\end{array}$ & $\begin{array}{l}\text { Upper - } \\
\text { Quartile }\end{array}$ & $\begin{array}{c}\text { SD } \\
\text { Years of vice }\end{array}$ \\
\hline
\end{tabular}


TABLE 4. Descriptive analysis

\begin{tabular}{lllllllllll}
\hline & Valid N & Mean & $\begin{array}{l}\text { Confidence } \\
\mathbf{9 9 5} \%\end{array}$ & $\begin{array}{l}\text { Confidence } \\
\mathbf{+ 9 5 \%}\end{array}$ & Median & Min & Max & $\begin{array}{l}\text { Lower - } \\
\text { Quartile }\end{array}$ & $\begin{array}{l}\text { Upper - } \\
\text { Quartile }\end{array}$ & $\begin{array}{c}\text { SD } \\
\text { Cigarettes per day }\end{array}$ \\
\hline & 24 & 9.6 & 6.5 & 12.6 & 8.0 & 2.0 & 30.0 & 5.0 & 10.0 & 7.2 \\
\hline
\end{tabular}

TABLE 5. Number of cigarettes per day declared by nurses with hand eczema

\begin{tabular}{lll}
\hline Cigarettes per day & Count & Percent \\
\hline 2 & 1 & 0.40 \\
4 & 1 & 0.40 \\
5 & 7 & 2.83 \\
6 & 1 & 0.40 \\
7 & 1 & 0.40 \\
8 & 2 & 0.81 \\
10 & 8 & 3.24 \\
20 & 1 & 0.40 \\
30 & 2 & 0.81 \\
Missing & 223 & 90.31 \\
\hline
\end{tabular}

\section{DISCUSSIONS}

The results of our study showed no correlation between smoking and hand eczema in healthcare workers. Indeed, a previous study confirmed an association between smoking and foot eczema, but not hand eczema. ${ }^{5}$ A large meta-analysis did not confirm smoking as a risk factor for hand eczema. ${ }^{6}$ Other studies from Scandinavia, however, reported an association between smoking and the severity of hand eczema and that smoking prolongs the healing process of hand eczema. ${ }^{7,8}$

\section{CONCLUSION}

In conclusion, our data does not support the idea that smoking is an independent risk factor for the development of occupational hand eczema during the COVID-19 pandemic.

\section{CONFLICT OF INTEREST}

Nothing to declare.

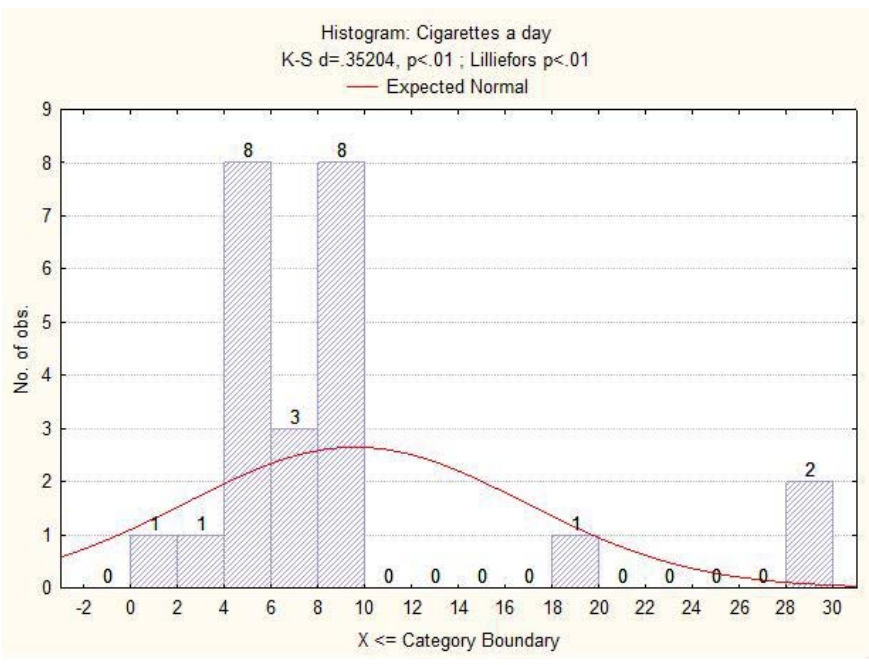

FIGURE 2. Distribution of cases and number of cigarettes per day

\section{REFERENCES}

1. Yan $\mathrm{Y}, \mathrm{Chen} \mathrm{H}$, Chen L, et al. Consensus of Chinese experts on protection of skin and mucous membrane barrier for health-care workers fighting against coronavirus disease. Dermatol Ther. 2020:e13310.

2. Lan J, Song Z, Miao X, et al. Skin Damage Among Health Care Workers Managing Coronavirus disease-2019. J Am Acad Dermatol. 2020;82:12151216.

3. Zimmer KA, Armbrecht ES, Burkemper NM. The association of smoking with contact dermatitis and hand eczema - a review. Int J Dermatol. 2018;57:375-387.

4. Wollina U. Smoking and the Skin. Skinmed. 2017;15:197-202.

5. Mortz CG, Bindslev-Jensen C, Andersen KE. Hand eczema in the Odense Adolescence Cohort Study on Atopic Diseases and Dermatitis (TOACS): Prevalence, incidence and risk factors from adolescence to adulthood. $\mathrm{Br}$ J Dermatol. 2014;171:313-323.

6. Lukács J, Schliemann S, Elsner P. Association between smoking and hand dermatitis - a systematic review and meta-analysis. J Eur Acad Dermatol Venereol. 2015;29:1280-1284.

7. Sørensen JA, Fisker MH, Agner T, et al. Associations between lifestyle factors and hand eczema severity: are tobacco smoking, obesity and stress significantly linked to eczema severity? Contact Dermatitis. 2017:76:138-145.

8. Olesen CM, Agner T, Ebbehøj NE, et al. Factors influencing prognosis for occupational hand eczema: new trends. Br J Dermatol. 2019;181:12801286 . 